\title{
New global AIDS programme trying to break with the past
}

Nine months or so after its formation, the policies of the new Joint United Nations Programme on HIV-AIDS (UNAIDS) are beginning to take shape. When it is fully operational some time next year, UNAIDS will coordinate international AIDS control and supercede the soon-to-be-defunct Global Programme for AIDS (GPA), which until now was the principal player in the global fight against AIDS (with occasional participation from other agencies). The new organization, which, like GPA, will be headquartered in Geneva, Switzerland, hopes to break with tradition by being less bureaucratic, by providing a voice, though not a vote, to non-governmental organizations (NGOs), and by strengthening its AIDS programme outside AIDS prevention and medical care such as in social and legal areas, for example, protection for orphans and women from discrimination.

According to Peter Piot, newly appointed executive director of UNAIDS, "the mechanism of control adopted four or five years ago, whereby efforts go mainly towards prevention, is no longer appropriate. Today, we cannot separate prevention, the treatment of those touched by AIDS and the impact of the epidemic on communities and families alike." Moreover, Piot believes that it is possible to treat people with AIDS, even in poor countries, with relatively inexpensive methods, like those now used to combat tuberculosis.

The determination of many donor nations to phase out GPA has played a role in the establishment of UNAIDS, set up in late 1994 by five agencies of the United Nations (UNICEF, the World Health Organization (WHO), UNESCO, the UN Development Programme and the UN Population Fund), in conjunction with the World Bank. In spite of an annual budget of roughly $\$ 80$ million, GPA was seen as unwieldy and inefficient. And it was no secret that interagency competition often led to a duplication of effort and less than optimal use of agency resources. The leadership of GPA's last executive director, Michael Merson, was also controversial.

In order to effect a smooth transition from GPA to UNAIDS when GPA's doors finally close this December, Piot has recruited a multidisciplinary team of 12 people - many of whom came from other UN agencies.

Although UN agencies and donor countries agree with the broad approach being taken by Piot and his transition team, they have been reluctant to accept some of the proposals. One controversial move has been the decision to include among the 22 members of the Programme Coordinating Board (which ratifies UNAIDS policies), not only a majority of representatives from developing countries, but also five representatives of NGOs.

This decision to provide greater representation to NGOs is intended in part to make better use of local resources and expertise. It is also part of a series of measures slowly being adopted to distance the programme from governmental influence. "Until now, in matters concerning AIDS, UN agencies have above all else supported the agendas of governments. We want to better respond to everyone's needs. To accomplish this we need to involve not only governments, but NGOs, the private sector and most importantly, local experts," says one UNAIDS official.

Preventing UNAIDS from becoming administratively top heavy is another objective. Fully staffed, UNAIDS is expected to have 190 employees; GPA, by comparison, employed 250 . Only densely populated countries, or those where the

AIDS epidemic is particularly severe (60 in all), will have a local UNAIDS staff member.

It remains to be seen whether UNAIDS will obtain the financial and political support needed to accomplish its goals. In July, its Coordinating Board approved a budget of $\$ 120$ to $\$ 140$ million for the coming two years, roughly the same as GPA's. Although the staff at UNAIDS is optimistic that contributions from the United States and Japan will be forthcoming, the level of expected support from some of the European nations, particularly Britain and France, is in some doubt. Simone Veil, health minister in the former Balladur government (under Mitterand's presidency), had pushed strongly for UNAIDS to be set up and had pledged \$12 million in support for one year. But, given the recent changing of the political guard in France, this level of funding is now far from certain. UNAIDS is not even mentioned in the revised 1995 French budget, which was approved in July. "Let's hope it will be included in the 1996 budget," says one UNAIDS official.

CATHERINE TASTEMAIN

Paris

\section{Industry blasts FDA disclosure rules}

With little or no fanfare, the US National Institutes of Health (NIH) and the US National Science Foundation (NSF) in mid-July issued final regulations on "Objectivity in Research," requiring investigators to disclose financial interests that might "directly and significantly affect the design, conduct, or reporting of research." Meanwhile, officials at the US Food and Drug Administration (FDA) are proposing their own version of tough new financial disclosure rules intended to keep bias from tainting the outcome of clinical trials in which agencyregulated products are being evaluated.

Although initial reactions from researchers at academic institutions seem to reflect at least lukewarm acceptance of the various new rules, representatives of drug companies and manufacturers of medical devices are up in arms about the new FDA proposals. The proposals, first made public late in 1994 (after which the FDA asked for comment and held a public hearing), call for corporate sponsors either to certify that clinical investigators evaluating new drugs, biologics (for example, interferons and interleukins) or medical devices have no financial conflict of interest, or to disclose pertinent financial information when sponsors do not provide the required certification. The proposed rules specify several situations where problematic conflicts of interest can arise for investigators. These include the following:

- When a study's outcome may affect the investigator's level of financial compensation from the sponsor;

- When sponsors provide an investigator with grants, retainers, honoraria or equipment;

- When the investigator holds a patent on the product being tested;

- When the investigator has an equity interest in the company involved.

Conceivably, agency officials could reject results from clinical trials in which such conflicts had not been duly reported. This prospect alarms even some of the more moderate commentators, including those who accept the new NIH and NSF regulations and otherwise sympathize with the FDA's efforts to set high ethical standards for clinical investigators. 